\title{
Assessing the Benefits of a One-Stop Medical and Financial Support Program: From the Standpoint of Patients of Eduardo L. Joson Memorial Hospital in the Philippines
}

Janneth D. Santiago

Dr. Paulino J. Garcia memorial research and medical center

Mabini St. Quezon Dist. Cabanatuan City,

Nueva Ecija, Philippines

Rossana M. Vasallo

Local Government Unit - Laur, Nueva Ecija, Philippines

Tablang Gabaldon Road, Brgy. 3, Laur, Nueva Ecija Philippines

Melody R. Dionisio

Maligaya National High School,

Maligaya, Palayan City, Nueva Ecija, Philippines

Francisca R. Binuya

Exequiel R. Lina High School, Poblacion Norte, Licab,

Nueva Ecija, Philippines

Rosemarie R. Casimiro

Nueva Ecija University of Science and Technology

Main Campus, Gen. Tinio St. Quezon District, Cabanatuan City,

Nueva Ecija, Philippines 
Vilma B. Ramos (Corresponding author)

\author{
Nueva Ecija University of Science and Technology \\ Main Campus, Gen. Tinio St. Quezon District, Cabanatuan City, \\ Nueva Ecija, Philippines
}

\begin{abstract}
Received: Sep. 15, $2021 \quad$ Accepted: Oct. 13, $2021 \quad$ Online published: Nov. 22, 2021
doi:10.5296/jpag.v11i4.19241～URL: https://doi.org/10.5296/jpag.v11i4.19241
\end{abstract}

\begin{abstract}
This study described the benefits of the Malasakit Center based on the perspectives and experiences of patients of Eduardo L. Joson Memorial Hospital. It employed mixed research methods and interviews as the primary data collection tool. The study was conducted in March 2020 with thirty patients and patient's relatives receiving services of the hospital. Most of the respondents are male and within the age bracket of 30 to 39 years old. All the participants reflected a positive response to Malasakit Center, as it lessened the burden of producing documentary evidences to avail of the services. A procedure observed prior to implementing the Malasakit program. This study also focuses on how the Center made the service more accessible. To further maximize its benefits, information dissemination needs to be widened and its location in the province and in the Philippines should be advertised for increase patronage. Posting of the requirements for availment of Malasakit Center services is likewise essential and may considerably increase the number of applicants for the services of the Center.
\end{abstract}

Keywords: financial assistance, Malasakit center, indigent patients, medical assistance

\title{
1. Introduction
}

Poverty and health are often encountered in cross-sectional and multidimensional studies. They are structurally linked to socio-political and economic aspects. And while poverty remains a serious global problem, public health is slowly becoming a commodity that most people cannot afford. The World Bank (2014) identifies this concern as financial because the poor cannot purchase their needs to ensure good health and well-being. This standing issue needs government intervention. The state needs to provide its citizens accessible healthcare programs through assistance and subsidies.

Financial assistance for hospitalization provided by the government is a go-to option for many Filipinos. It enables many to avail medical treatment for a reduced cost or with an added resource to pay for the medical expenses. However, one has to go through tedious processes to avail financial assistance, as many people in need are often overwhelming. The burden of proof is passed on to the shoulders of the citizens availing assistance from the government. Numerous documents need to be processed and submitted, including but not 
limited to certificate of indigency, certificate of tax exemption, among others. The work these processes require of the marginalized is overwhelming and costly, and documents come with a price. This might seem ironic because time is of the essence, and the clock is ticking for the people who need financial assistance for medical treatment, especially that many hospitals implement payment first policy.

The marginalized experience difficulties in the processes; it calls for a more systematic and accessible program to extend government aid. Thus, the emergence of policies and programs paved the way for the 2019 Malasakit Center Act. A one-stop medical and financial support program for indigent patients.

On December 2, 2019, Republic Act No. 11463, otherwise known as the Malasakit Center Act of 2001, was signed into law by President Rodrigo Duterte out of the bill proposed by Senator Christopher "Bong" Go. The Act established the Malasakit Program and institutionalized Malasakit centers in public hospitals. The Malasakit Center serves as a one-stop-shop for all government medical and financial support for Filipinos especially, indigent patients. This program aims to promote convenience by providing an avenue where patients can access financial and medical assistance from agencies such as PhilHealth, Philippine Charity Sweepstakes Office, and the Department of Social Welfare and Development all at once. The program also aims at bringing down, at the lowest amount possible, the hospital bill, including out-of-pocket expenditures of impoverished Filipinos. As quoted from the statement made by the Department of Health (DOH) Secretary, Francisco Duque III, the program complements the Universal Health Care Law,

"We are glad we now have this law that truly reflects the Duterte
administration's brand of people-centered service delivery. We
guarantee that our patients need medical assistance, dignity,
respect, and malasakit. This complements our implementation of
the Universal Health Care law." ("PRRD Signs Malasakit Center
Act", 2019).

In January 2019, the program was formally launched. One of the hospitals that adopted it is Eduardo L. Joson Memorial Hospital, one of the public hospitals in Cabanatuan City in Nueva Ecija. The Malasakit Center accepts applications for financial assistance and directs them to various government agencies. This significant step in providing government assistance comes with a budget. The budget comes from the taxpayers' money and is therefore subject to the scrutiny and evaluation of the taxpayers as to whether or this program makes headway. The study aims to determine the experiences and perceived benefits of the patients about the Malasakit Center a year after it came into existence.

This section provides additional information on similar programs implemented in different countries, as cited from the available literature. The data also offer a point of comparison between the approaches currently being employed to ensure higher health coverage of the public, especially the marginalized. 
1.2 Health and Poverty

Poverty is undeniably one of the major hindrances for the marginalized not to seek professional intervention when their health is put at risk. A study conducted in Chittagong, Bangladesh, by Herdman et al. (2016) found that most of the poor delay decision making due to monetary constraints. It was reported that:
"Poor participants were more likely to attribute delays in decision-making and travel to a lack of money $(P<0.001)$, and more likely to face catastrophic expenditure of more than $25 \%$ of monthly household income $(P<0.001)$."

While most researchers utilize poverty indices as indicators of healthcare deprivation, some believe that poverty is more than that. In the study conducted by Chaudry and Whimer (2016), they wrote:
"As we have argued herein, poverty and low income appear to be causally related to poor child outcomes, particularly cognitive and educational outcomes. Poverty and low income likely exert effects through material hardships, family stress, and reduced parental cognitive input and spending. And it is not just poverty per se that matters, but it is timing, duration, and concentration in the community context."

This goes to show that healthcare is not something that everyone can afford (Ramos 2021). The marginalized people are the most vulnerable to health risks. And poverty is not making things better for them. Hence, government intervention in the processing of financial and medical assistance must be improved.

\subsection{Government Healthcare Services across the Globe}

\subsubsection{United Kingdom's National Health Service}

The United Kingdom's National Health Service (NHS) was founded in 1948 and funded from general tax. It arose from a long-held belief that proper treatment should be available to all people, regardless of their financial circumstances, one of the NHS's founding principles. Services such as prescriptions, optical and dental care are accessible to more than 64 million U.K. residents at the point of use (Grosios et al., 2010).

The Commonwealth Fund declared in 2014 that the NHS was the most remarkable compared to the healthcare systems of ten other nations. These are Australia, Canada, France, Germany, Netherlands, New Zealand, Norway, Sweden, Switzerland, and the United States of America because of its efficiency, effective care, safe treatment, coordinated care, patient-centered care, and low cost.

The Health \& Social Care Act 2012 moves the responsibility for pricing from the Department of Health to a shared responsibility for NHS England and NHS Improvement. The NHS began operations in 1948 with a budget of 437 million euros, which is about 15 billion euros 
nowadays. In 2015, the NHS had a budget of 116.4 billion euros.

\subsubsection{Canada's Health Care System}

Canada's publicly funded healthcare system bears the name "Medicare." Instead of having a single national plan, the country has 13 provincial and territorial health care insurance policies. All Canadians have reasonable access to medically necessary hospital and physician treatments without paying out of pocket. The provincial and territorial governments and the federal government share roles and duties for healthcare services. The provinces and territorial governments are responsible for planning, organizing, and delivering healthcare services to their citizens. Through the Canada Health Act, the federal government sets and enforces national healthcare standards, provides funding support for provincial and territorial healthcare services, and supports healthcare services to specific groups that perform other health-related functions.

The Canadian government encourages citizens to prioritize primary health care. The government sees that first-contact health care, continuity of care from diagnosis to recovery, ease of movement, and extra coverage for the elderly, children, women, and residents requiring social assistance are provided. Out-of-pocket payments and private health insurance policies are used by those who do not qualify for supplemental benefits under government plans.

\subsubsection{United States of America's Health System}

According to the Center for Medicare and Medicaid Services (2014), the United States does not subscribe to a uniform healthcare system, has universal healthcare coverage, and only recently approved legislation requiring practically everyone to have healthcare coverage. The U.S. healthcare system is best described as a hybrid system. It does not operate nationally or have a single-payer national health insurance system or a multi-payer universal health insurance fund.

In $2014,48 \%$ of the U.S. health care spending came from private funds, with $28 \%$ coming from households and $20 \%$ from private businesses. Two hundred eighty-three million people (89.6\% of the U.S. population) reportedly have health insurance during the same year. Medicare covers 61 million, Medicaid covers 50 million people, and Veterans Administration or other military care covers 14 million. Although 32 million people still lack health insurance (Smith and Medalia, 2014).

\subsubsection{Philippine Healthcare System and legal bases}

The Philippine government aims to provide comprehensive health insurance to all Filipinos, especially the marginalized. The National Health Insurance Act or RA 7875 was passed into law in 1995, establishing social health insurance (SHI). The Individually Paying Program (IPP), a voluntary component of the country's health insurance system, is one of the Philippine Health Insurance Corporation's (PhilHealth) schemes. Individuals who choose to pay for their membership are registered in the IPP system. Self-employed, self-earning, and individuals in occupations where there is no official employer-employee connection are 
among them. Medical care in the Philippines has remained prohibitively expensive. The administration has prioritized establishing universal health coverage for the poorer segments to access health care without becoming impoverished. The IPP's voluntary nature has become a critical focus for the SHI's expansion to achieve universal coverage (Silfverberg, 2016).

The importance and comprehensiveness of the health system are embedded in Section 6 of the Republic Act 10606, otherwise known as the National Health Insurance Act of 2013. Aligned to the principles of universality and compulsory coverage, the program shall ensure the sustainability of range and continuous enhancement of the quality of service. Furthermore, Section 3 (c) of the Act emphasizes the need to "prioritize and accelerate the provision of health services to all Filipinos, especially to segments of the population who cannot afford such services." All indigents not enrolled in the program shall prioritize the use and availing of the services and facilities of government hospitals, health care personnel, and other health organizations until they are subsequently enrolled in the program.

Under the ambit of the Universal Health Care (UHC) or Kalusugang Pangkalahatan (K.P.), PhilHealth is mandated to ensure health insurance coverage of all Filipinos, especially the most vulnerable. Despite Sin Tax collections, local government sponsorship, and other sources, statistics and anecdotes have shown that PhilHealth does not yet cover many poor. Ergo, it is deemed necessary that different mechanisms of capturing the poor shall be undertaken. A means of enrollment at the "Point of Care" shall be established to ensure that PhilHealth covers all poor in dire need of quality health services in government hospitals. Purchasing health services is very important for the Kalusugan Pangkalahatan (K.P.) initiative to attain adequate coverage. PhilHealth, the country's social health insurance, has prioritized membership expansion to shift focus to boost the reimbursement rate should $75-85 \%$ rate of coverage is reached. This is to truly minimize the likelihood of households falling into poverty due to illness. To do this, PhilHealth defines the services that members require, accredits providers, determines the cost of services, negotiates a fair price with providers, and pays providers promptly with little out-of-pocket expense from members (Picazo et al., 2012).

The Philippine government's National Health Insurance Program (NHIP) is a social health insurance system partially supported by tax-based financing. It provides benefits on a fee-for-service basis up to a defined maximum (Tobe et al, 2013). The median out-of-pocket payment is 3,016 pesos. The overall expenditures are typically associated with varying depending on the patient's membership type, disease severity, age, residential area, length of hospitalization, and hospital level. Although the current NHIP reduces the size of out-of-pocket payments, beneficiaries are not entirely free from the risk of large out-of-pocket payments, despite NHIP's attempts to mitigate this by setting different benefit ceilings based on the level of the hospital and the severity of the disease. To reduce large out-of-pocket payments and increase financial risk protection, it is essential to ensure more investment for health from social health insurance and tax-based government funding. Also, shifting of provider payment mechanism from a fee-for-service to a case-based payment method might help since this is only partially implemented. 
Meanwhile, children under five are more likely than other age groups to need in-patient treatment (Puyat, 2013; 2008 National Demographic and Health Survey). These children are likely to become ill and in danger of incurring enormous medical costs if they do not have health insurance. PhilHealth only covered $33.93 \%$ of the under-5 population, and $67.59 \%$ of hospitalized PhilHealth dependents used PhilHealth to pay for the bills. Age and educational attainment of the family head and the area and wealth index were essential determinants impacting coverage in a logistic regression study. Furthermore, it was discovered that confinement in a private institution for more prolonged periods increased the likelihood of PhilHealth dependents using in-patient benefits.

Quimbo et al. (2008), conducted between 2003 and 2007, determined how people used social health insurance in 30 hospital districts in the Philippines' core regions. The study's data also uses the findings of a Quality Improvement Demonstration Study (QIDS) composed of detailed patient data from exit interviews with children under five years old done in seven waves throughout public hospital districts in the Philippines' four significant regions. Using logistic regression, these data were used to estimate and identify predictors of underutilization of insurance benefits, defined as the likelihood of not filing claims despite having valid insurance coverage. The same study also concluded that the high level of insurance underutilization by insured patients in the QIDS sites undermines the potentially positive impact of social health insurance on the marginalized. "Underutilization" suggests the ineffective distribution of public funds and the failure to reach a significant proportion of households.

In 1996, Chakraborty's research revealed that the Philippines implemented a demand-side program for impoverished households comparable to sponsored programs in low- and middle-income nations. The goal was to make it easier for low-income families to get critical health care without paying much money. It was integrated into the National Health Insurance Program (NHIP) in the Philippines, unlike similar programs in other countries that can stand alone. This is a crucial design feature that allows for efficient risk pooling and redistribution. Chakraborty (2011) also did a case study on the Philippines' healthcare coverage program for low-income families using the 2011 World Bank report on the Philippines' government for universal health coverage (UHC). The Philippines serves as an example for other nations looking to implement similar systems for low-income households. There is no risk of funding instability because the national government has incorporated finance for low-income families in the medium-term national expenditure budget.

In the Philippines, PhilHealth is gradually improving its contract implementation and monitoring systems. However, the main question presently facing Health Care for Filipino People (HCP) is whether these redesigned efforts could quickly address impoverished households' lack of access to high-quality, low-cost services. Supply limits exist, and facilities will need to be updated to receive PhilHealth accreditation. Accredited health care facilities will be held accountable for the services they provide. Where state services are unavailable, incentives for the private sector to reach out to poor households must be used. Much hinges on PhilHealth's ability to buy health services efficiently. Another constraint is the capacity of local government unit (LGU) facilities to respond to the redesigned 
PhilHealth incentives. Another question is whether the Department of Health and PhilHealth will quickly develop the monitoring and evaluation systems required to track the implementation of Health Care for Filipino People and make necessary in-flight adjustments.

Citing the work of Dr. Noel Juban of the University of the Philippines Manila, who led a systematic review of the specific issues and priority public health programs, Suerte (2013) wrote an article to provide lessons for the country's NHIP as it strives to achieve its goal of universal health coverage.

Another comprehensive research assessment describing existing voluntary and compulsory health insurance programs was conducted to compare the two plans. Results showed that mandatory health insurance is only offered to the formal sector in low- and middle-income countries and only voluntarily for the informal sector. It was also found that employment, presence of illness, level of education, and income are significant determinants of enrolment or retention. The study suggests implementing a co-payments scheme to avoid moral hazards and adverse selection and streamlining enrolment procedures by allowing on-site enrolment and offering employment stability to the informal sector. Understanding the characteristics of the population will be helpful in the formulation of concrete strategies to expand health insurance and the achievement of Universal Health Care for the Filipino people.

The Philippines has enacted laws to improve the country's health system further. First is Republic Act No. 11463, which seeks to give convenience and accessibility to all Filipinos who need medical and financial assistance from the government by bringing all the concerned agencies under one roof. It aims to provide people-centered health services and ease indigent patients' financial burden (Malasakit Center, 2020). The second is Republic Act No. 10606, which is a mandatory health care scheme for Filipinos. It secures the coverage of the marginalized by assisting and prioritizing the health care needs of the underprivileged, sick, elderly, persons with disabilities (PWDs), women and children and provides free health care services to indigents (Fernandez et al., 2014). The third is Republic Act No. 11223, signed into law on February 2, 02019, by President Rodrigo Duterte. This guarantees equitable access to affordable and health quality services for all Filipinos. Under this law, PhilHealth will have expanded coverage to include free consultation fees, laboratory tests, and other diagnostic services (Montemayor, 2019). All Filipinos are granted access to a full spectrum of health care. This can be expected for medical, dental, mental, and emergency health services. Citizens no longer need to present PhilHealth ID to acquire benefits. Concurrently, indigent Filipinos and those who live in remote areas will also be given priority when ensuring access to health services and assistance (Tomacruz, 2019).

In Davao, the program was localized and named "Lingap para sa Bayan" in 2020. Agencies like the Department of Social Welfare and Development, the Philippine Health Insurance Corporation, and the Philippine Charity Sweepstakes Office are made accessible into one Center. This was implemented to make medical assistance processing easier and limit the need to go to different places to request assistance and supporting documents (Rizal, 2017).

This study will benefit the hospital administrators as it will provide insights on the status of Malasakit Center and how the existing policies may be improved. The study may serve as a 
means of informing the public of the services offered by the Center.

\subsection{Assessment of Healthcare Assistance and Services}

As with any other service provided by the government or non-government organization, healthcare assistance and services must undergo evaluation. Evaluation is commonly used as a tool in assessing whether the government agency offers quality services or not. Assessment, however, is not an easy task. Specific guidelines must be implemented. Sometimes, even the law is involved.

In the United States, it has always been a difficult challenge to layout provisions that will ensure quality health services. The authors of an evidence-based handbook for nurses, Steinwach and Hughes (2008), believe that it can yield accurate quality assessment results through health services research (HSR). They wrote:

"Drawing on theories, knowledge, and methods from a range of disciplines, HSR is a multidisciplinary field that moves beyond basic and applied research, drawing on all the health professions and many academic disciplines, including biostatistics, epidemiology, health economics, medicine, nursing, operations research, psychology, and sociology."

Most of the time, government agencies whether local and national have to undertake assessment of their practices as they establish trust and confidence of citizens (Gabriel and Castillo, 2020) they even undergo accreditation to measure the quality of services that they provide. The quality of services as important ingredient of citizens support to the government (Gabriel,2017). However, some studies suggest that beneficiary review is one of the most critical evaluation methods one can look into when conducting research. Beneficiaries play an essential role in these types of research as they directly experience the services. At the same time, they are also the ones who are often disregarded. Twersky (2013) argued:

"Perhaps we don't trust the beneficiaries' point of view. Maybe we're fearful of what they might say-that without the benefit of "expertise," they might be misinformed or wrong. Perhaps we're scared that we will learn something that calls our approach into question."

In a study conducted by Woelfel et al. (2015), a total of 576 beneficiaries were asked to participate. The study revolved around the beneficiaries' knowledge, attitude, and perception about a Medicare prescription drug. Their findings report:

"Forty-seven percent of beneficiaries claimed to be "very" or "extremely" satisfied with Part D, yet only $40.3 \%$ of those with a prescription drug plan (PDP) rated their plan as "very good" or "excellent." Those automatically enrolled into their plan by Medicare were significantly less satisfied with their plan $(P=$ 0.048)." 
The research findings also reported a racial disparity among the participant's responses to insinuate the matter further. Such cases suggest that agencies follow a thorough review from accreditors and particularly from beneficiaries.

\subsection{Statement of the Problem}

The study is aimed at answering the following questions:

1. How may the respondents be described in terms of:

$$
\begin{aligned}
& \text { 1.1. Age } \\
& \text { 1.2 Sex } \\
& \text { 1.3. Civil status }
\end{aligned}
$$

2. How may the patients' perception of the Malasakit Center be described in terms of:

2.1 Processing of Financial assistance

\subsection{Immediate Benefits}

\subsection{Other services}

3. How may the challenges in the delivery and availing of services of the Malasakit Center be described?

4. What policy recommendations may be offered based on the findings of the study?

\subsection{Theoretical Framework}

\subsubsection{Systems Theory and Healthcare System Studies}

Introduced by Karl Ludwig von Bertalanffy in 1920, Systems Theory continuously expands to great use in multiple dimensions and fields of research, including but not limited to social work, psychology, and engineering.

Social Work License Map explained how researchers might utilize Systems Theory as a theoretical framework. The article highlighted that systems theory in social work comes from the concept that various factors affect one's behavior.

Chen and Stroup (1993) used General Systems Theory as a framework for the topic, "science and technology education for all." They articulated:

"The various efforts to implement system thinking in educational contexts are reviewed, and three kinds of learning environments are defined: expert presentation, simulation, and real-world. A broad research agenda for exploring and drawing out the educational implications of system thinking and learning are outlined. The study of both real-world and simulated learning environments is advocated."

This theoretical framework, Systems Theory, appeared in social work focusing on health systems-related studies. For example, in their paper published in National Center for Biotechnology Information (NCBI), Anderson (2017) emphasized the role of Systems Theory in developing better healthcare services by reconciling instead of isolating the part of the systems in the individual. He wrote: 
"Dr. Levitt argued that 2-3\% of healthcare professionals are simply bad seeds and that the key to quality improvement lies in removing these individuals from the field. He had robust literature to support his claims (though some might question the risk adjustment methodologies employed). But Dr. Levitt failed to understand that individual accountability and Systems Theory are not mutually exclusive. One can hold individuals responsible where appropriate while simultaneously looking holistically at the system to identify a weakness that allows for or even enables adverse events. "

Similarly, researchers Chuang and Inder (2009) laid a perspective on identifying the relationship between accreditation reports and actual outcomes and the perception of those functioning within the systems and the actual results. This led them to the outcome, written:

"The proposed model discovers a fourth implicit relationship, feedback between quality performance reporting components and choice of accreditation components that is likely to play an important role in health care outcomes. An example involving accreditation surveyors is developed that provides a systematic search for improving the impact of accreditation on quality of care and hence on the accreditation/performance correlation." (Chuang and Inder, 2009)

This new perspective emphasizes the weakness that accreditation has and that there are more opportunities for further examinations not only of healthcare departments but of other agencies of the government. Why is this problem important?

In his study, Bertalanffy emphasized the framework's concepts of emergence, hierarchy, control, and communication (Drack \& Pouvreau, 2015). A general model of complex systems can be stated in terms of a hierarchy of organizational levels. Complex systems' safety and quality features are emergent properties of the system as a whole, not of individual system components. An open and dynamic complex system, such as the healthcare system, is considered a collection of interconnected subsystems kept in a state of dynamic equilibrium by feedback loops of information and control, according to the second set of basic system theory ideas. Specifically, a set of safety and quality restrictions associated with the behavior of system components or subsystems manage their relevant emergent features. In complex systems, regulation to necessary standards is the most prevalent type of safety constraint enforcement, and it is articulated through hierarchical regulation relationships.

As the Systems Theory developed over time, it became one of the frameworks used in social work research papers. This framework is used to describe human behavior as being affected by multiple factors in the environment.

In the literature review, Anderson (2017) and Chuang and Inder (2009) explained how the system is more than a simple interconnectedness of system components. The two studies paved the way to a concept that there are internal and external components to a system, both 
employees and accreditors, respectively. In threading this theory to the paper, researchers recognize the need to assess whether the system is functioning accordingly by gathering the perception of its beneficiaries, in this case, the external components of the Malasakit Centers.

In recognizing Systems Theory as a Social framework that embodies concepts of human behavior, the paper focused on identifying perceptions of Malasakit Center beneficiaries considering the program's effectiveness.

\subsection{Research Paradigm}

Figure 1 below shows the research paradigm of the study. It illustrates a logical model that explains the variables analyzed and the relationship of each one.

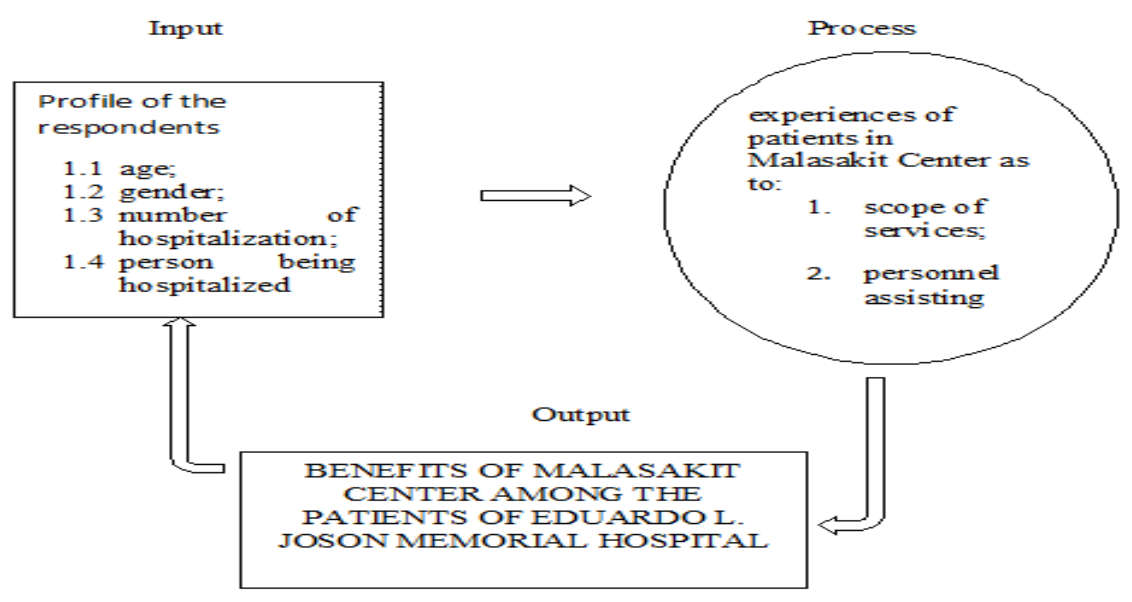

Figure 1. The Research Paradigm of the Study

The research paradigm is encapsulated in an Input-Process-Output (IPO) framework. The Input part is composed of the profile of the respondents. Following the input is the Process part, where most of the data gathering and analysis take place. And the last part consists of the Output. These three parts works in harmony to help the researchers yield desired outcomes.

The profile of the participants is part of the analysis as it may provide crucial information on their decision to avail of the financial assistance and the service provided by the Malasakit Center. The perceived benefits will be tied to the patients' and their relatives' experiences in transacting with the personnel assigned in the Center and the service availed. The study's end goal is to raise awareness about the Malasakit Center based on the information provided by the participants, the perceived benefits, and areas needing improvement.

\section{Method}

This section presents the locale of the study, the participants, and the procedures are undertaken to answer the statement of the problem. 


\subsection{Research Locale}

The data was obtained from Eduardo L. Joson Memorial Hospital, a 54 bed-capacity hospital in Cabanatuan City in Nueva Ecija, Philippines. The said hospital hosts a Malasakit Center where the marginalized may refer when they need financial and medical assistance.

\subsection{Participants}

The researcher interviewed thirty (30) respondents who are either patients or relatives receiving service from the Malasakit Center at Eduardo L. Joson Memorial Hospital. They were purposely recruited based on their experience, availability at the time of data collection, capacity to provide helpful information about the topic, and willingness to participate.

\subsection{Data Gathering Tool}

The researcher used self-made, semi-structured interview questions as the primary tool in data gathering. The first part contains questions eliciting responses on the profile of the respondents. The second part includes both closed and open-ended questions that collect data on patients' experiences when they availed themselves of the services offered in the Malasakit Center.

\subsection{Data Gathering Procedure}

The researchers personally approached the respondents in the waiting area of the hospital. The purpose of the study was explained. They were informed that their participation is voluntary and that they may withdraw participation at any time or may opt not to answer questions that they are not comfortable with. The responses were recorded, treated with descriptive statistics, and statements were analyzed based on content. The study also involved field observation wherein the researcher had the opportunity to observe the process, which helped confirm the responses and claims of the participants.

\section{Results}

This section presents the findings derived from the information provided by the participants during the data collection process.

\subsection{Profile of the Participants}

Table 1. Profile of the participants based on Sex

\begin{tabular}{ccc}
\hline Sex & Frequency & Percent \\
\hline Male & 17 & 56.67 \\
Female & 13 & 43.33 \\
\hline
\end{tabular}

The majority of the participants $(n=17,56.67 \%)$ are males. More male patients are admitted to the ward and emergency room during the scheduled days of data collection. Also, most of the relatives accompanying the patients when they were discharged are males who can carry 


\section{Macrothink}

the baggage and other materials used by the patient during hospitalization. However, numbers do not deviate too much as female respondents $(n=13)$ comprise $43 \%$ of the participants. The respondent patients and the relatives are between 30-60 years old, as reflected in Table 2

Table 2. Profile of participants based on age

\begin{tabular}{ccc}
\hline Age & Frequency & Percent \\
\hline $30-39$ & 15 & 50.00 \\
$40-49$ & 7 & 23.33 \\
$50-60$ & 8 & 26.67 \\
Total & 30 & 100 \\
\hline
\end{tabular}

Half of the thirty patients and relatives who participated in the study are within the 30-39 age group. This age group is within the working and reproductive age. People under the age group are typically active and mobile. They are prone to accidents, have conditions that require treatment, or have to be admitted before and days after delivery of a child. It can also be gleaned that the following higher percentage of the sample population belongs to the 50-60-year-old bracket. They are the relatives or parents of the patients who are hospitalized. They typically accompany the patients because the parents and spouse are authorized to sign papers on the patients' behalf.

Table 3. Profile of the Participants based on number of times hospitalized

\begin{tabular}{lcc}
\hline $\begin{array}{c}\text { Number of times } \\
\text { hospitalized }\end{array}$ & Frequency & Percent \\
\hline 1 & 7 & 23.33 \\
$2-4$ & 15 & 50.00 \\
5 -above & 8 & 16.66 \\
Total & 30 & 100 \\
\hline
\end{tabular}

Half of the participants reported that they or their patients had been hospitalized 2-4 times. Despite the need to be hospitalized, purchase prescriptions, and pay daily confinement rates, many opted to avail of the assistance since this is like hitting two birds in one stone. They can be treated and seen by medical professionals at a reduced cost. When asked who frequently avail of the service, $40 \%(n=12)$ said that usually, it is their spouse with a particular illness or 
their wife who delivered a child. Others, $26.67 \%(n=8)$, apply for financial assistance to cover the expenses of their newborn or a child who has to be admitted. Another most frequent reason for availing medical services is dialysis $(n=8,26.67 \%)$ and check-ups $(n=5,16.67 \%)$.

\subsection{Patient and Relatives' Experiences Before the Institutionalization of Malasakit Center}

Table 4. Experiences before the institutionalization of the Malasakit Center

\begin{tabular}{lcc}
\multicolumn{1}{c}{ Experience } & Frequency & Percent \\
\hline Paying own bills & 5 & 16.67 \\
$\begin{array}{l}\text { Too many requirements before } \\
\text { they can avail the financial }\end{array}$ & 22 & 73.33 \\
$\begin{array}{l}\text { assistance } \\
\text { Too many offices in the hospital } \\
\text { are need to seek signatures before } \\
\text { release }\end{array}$ & 3 & 10 \\
Total & 30 & 10 \\
\hline
\end{tabular}

According to participants, before establishing the Malasakit Center, they have to go to different offices, talk to several employees, and bring with them documentary evidence. One of the participants even recalled that,

"Ang daming hinihingi sa aming papeles, umpisa sa indigency certificate hanggang sa pag aaply sa Point of care (POC), pabalik balik kami ang laki ng nauubos namin sa pamasahe at pag aasiskaso ng papeles" (There are a lot of papers and certificates that we are providing, and we need to allot so much time and money to secure it).

This is perhaps one of the realities in Philippine bureaucracy adversely affecting its efficiency in the delivery of social services. This practice is sometimes referred to as red tape (Gabriel 2018)

The majority $(n=22,73.33 \%)$ disclosed that sometimes they are discouraged from availing the services due to requirements such as a certificate of indigency and proof of Philhealth contributions. 


\section{Macrothink}

Table 5. Experiences in the processing of financial assistance

\begin{tabular}{lcl}
\hline Experience & Frequency & Percent \\
\hline $\begin{array}{l}\text { Services from the Department of } \\
\text { Social Welfare and Development, the }\end{array}$ & 30 & 100 \\
Philippine Health Insurance Corporation, \\
and the Philippine Charity Sweepstakes \\
$\begin{array}{l}\text { Office are processed by the personnel in } \\
\text { the Malasakit Center } \\
\text { The Center is like a One-stop-shop where } \\
\text { services are accessible under one roof } \\
\quad \text { Total }\end{array} \quad 30$ & 100 \\
\end{tabular}

All of the participants agreed that the establishment of the Malasakit Center had expedited the processing of services from agencies such as the Department of Social Welfare and Development, Philippine Health Insurance Corporation (PhilHealth), and the Philippine Charity Sweepstakes Office (PCSO). It also minimized the time consumed traveling and the expenses incurred in reproducing and submitting voluminous papers. This is likewise a translation of the Republic Act No. 11032, also known as the "Ease of Doing Business and Efficient Government Service Delivery Act of 2018". It was signed into law to ensure that government service, regardless of its nature, will be the primary consideration in public office, reducing turn-around time and increasing the level of performance as part of the process (Miranda et al., 2021).

Furthermore, the positive impact from the healthcare services provider is similar to a study conducted by Woelfel et al. (2015), where more than 576 participants were asked.

\subsection{Benefits From the Malasakit Center}

Table 6. Immediate benefits experienced through the Malasakit Center

\begin{tabular}{|c|c|c|}
\hline Experience & Frequency & Percent \\
\hline $\begin{array}{l}\text { The Center's } \\
\text { one-stop-shop set-up } \\
\text { minimizes the burden } \\
\text { among patients and } \\
\text { their relatives }\end{array}$ & 30 & 100 \\
\hline $\begin{array}{l}\text { The personnel quickly } \\
\text { and immediately } \\
\text { address queries }\end{array}$ & 30 & 100 \\
\hline Total & 30 & 100 \\
\hline
\end{tabular}

The Malasakit Center is a component of the Universal Health Care Program, a cornerstone of the Philippine development directions to remove inequities in health outcomes. The findings revealed that the Malasakit Center did provide convenience in processing financial assistance 
since the requests are accepted and processed by the Center and forwarded to the DSWD office following the procedure stipulated in the guidelines on the Assistance to Individuals in Crisis Situation (AICS). The Malasakit Center caters even the requests to the PCSO and politicians. The participants also have a positive experience with the person they described as approachable and ready to answer their queries regarding the services and requirements they have to submit. This is in line with the theory by Bertalanffy that the whole system is all its components working together in harmony to provide optimal results.

The Malasakit Center is manned by representatives from the DOH, DSWD, PCSO, and PhilHealth. The designated DOH, DSWD, and PCSO representatives process and approve medical and financial assistance requests. The PhilHealth representative addresses PhilHealth-related concerns and processes the documents submitted as a prerequisite to receiving assistance.

\section{Conclusion}

As poverty remains rampant, many marginalized people in the country have little to no access to healthcare and need financial assistance from the government. The government provided an id embodied in the law to answer the citizens' needs, like the Malasakit Center.

This study, conducted in 2020, a year after the Malasakit Center was launched, revealed the challenges the patients and relatives encountered in availing financial assistance before the Center was institutionalized. Many respondents mentioned that they had to go to the barangay to secure a certificate of indigency and to different offices for the other documentary requirements. Doing so adds up to the financial burden since they spend money for the fare, transportation costs, and reproduction of documents. Sometimes the tedious procedures lead to the patients not receiving medical treatments on time.

The participants believed that the Malasakit Center did operate based on purpose. Having representatives of the DOH, DSWDO, PCSO to accept requests and process documents in one roof made the service accessible. As perceived by the participants, it brought the relevant government departments in one roof and their services closer to the patients and relatives who are racing against time to produce the financial requirements for their treatment or discharge.

\section{Recommendations}

For the government, further improvements can be made in implementing programs to aid the Filipino people. For example, establishing more Malasakit Centers where the population is dense and making healthcare more accessible for everyone.

For future researchers, another study may be conducted in other areas and with more participants. A year after the opening of the Malasakit Center, many are still not well-informed about the services offered and the requirements for their availment. To increase reach, information about Malasakit Centers, the services offered, eligibility, and the conditions may be posted in conspicuous places within and outside ELJMH, including the barangay health centers. Information about the Center may be included as part of admission orientation. 
To government agents, not everyone is aware that they are entitled to receive aid from the government and that doing so would no longer require them to go through tedious and costly processes. The researchers recommend that government agents spread this kind of awareness to indigent Filipinos.

\section{References}

Anderson, B. R. (2016). Improving health care by embracing Systems Theory. The Journal of thoracic and cardiovascular surgery, 152(2), 593-594.

https://doi.org/10.1016/j.jtcvs.2016.03.029

Chakraborty, S., Schieber, G., Picazo, O., \& Tandon, A. (2011). "Transforming the Philippine Health Sector: Challenges and Future Directions." he International Bank for Reconstruction and Development, the World Bank, Washington, DC.

Chaudry, A., \& Wimer, C. (2016). Poverty is Not Just an Indicator: The Relationship Between Income, Poverty, and Child Well-Being. https://doi.org/10.1016/j.acap.2015.12.010

Chen, D., \& Stroup, W. (1993). General system theory: Toward a conceptual framework for science and technology education for all. J Sci Educ Technol, 2, 447-459(1993). https://doi.org/10.1007/BF00694427

Chuang, S., \& Inder, K. (2009). An effectiveness analysis of healthcare systems using a systems theoretic approach. BMC Health Serv Res 9, 195(2009). https://doi.org/10.1186/1472-6963-9-195

Drack, M., \& Pouvreau, D. (2015). On the history of Ludwig von Bertalanffy's "General Systemology", and on its relationship to cybernetics - part III: convergences and divergences. International Journal of General Systems, 44(5), 523-571.

Fernandez, J. et al. (2014). Overview of Devolution of Health Services in the Philippines. International Electronic Journal of Rural and Remote Health Research, Education, Practice and Policy.

Gabriel, A. G. (2017) Transparency and accountability in local government: levels of commitment of municipal councillors in Bongabon in the Philippines. Asia Pacific Journal of Public Administration, 39(3), 217-223.

Gabriel, A. G. (2018) Bureaucratic Red Tape in the Philippines. In: Farazmand A. (eds) Global Encyclopedia of Public Administration, Public Policy, and Governance. Springer, Cham. https://doi.org/10.1007/978-3-319-31816-5_3523-2

Gabriel, A. G., \& Castillo, L. C. (2020). Transparency and Accountability Practices of Local Government Units in the Philippines: a Measurement from the Ground. Public Organiz Rev 20, 437-457 (2020). https://doi.org/10.1007/s11115-019-00450-8

Grosios, K., Gahan, P. B., \& Burbidge, J. (2010). Overview of healthcare in the U.K. EPMA J. 2010 Dec, 1(4), 529-34.

Health \& Social Care Act 2012 (2012). Accessible at 
https://www.ilo.org/dyn/natlex/docs/ELECTRONIC/92503/107788/F1919416226/GBR92503 .pdf

Herdman, MT, et al. (2016). The Relationship between Poverty and Healthcare Seeking among Patients Hospitalized with Acute Febrile Illnesses in Chittagong, Bangladesh. Accessible at https://journals.plos.org/plosone/article?id=10.1371/journal.pone.0152965

Miranda, S., Garcia, R., Asuncion, A. F., Bilbao, S. R., Ong, D. U., Ramos, V. B., Antonio, OCC., Casimiro, R. R., \& Gabriel, A. G. G. (2021). Move and Learn Perceived Benefits and Challenges of Job Rotation in a Government Hospital in the Philippines. International Journal of Management, 12(1).

Montemayor, M. T. (2019). Health for all Filipinos: Universal Healthcare Law.

Picazo, O. F. (2012). PhilHealth Now and Then: An Assessment of the National Health Insurance Program, 1995-2012. Report submitted to the Philippine Health Insurance Corp

Poverty and health (2014, August 25). Retrieved August 3, 2021, from https://www.worldbank.org/en/topic/health/brief/poverty-health

PRRD Signs Malasakit Center Act (2019, December 3). Retrieved from https://doh.gov.ph/doh-press-release/prrd-signs-malasakit-center-act

Puyat, MEA D. (2013). "Factors Influencing PhilHealth Coverage and In-patient Benefit Utilization of Filipino Children under Five," Discussion Papers DPDP 2013-37, Philippine Institute for Development Studies.

Quimbo, S, Florentino, J, Peabody, J. W., Shimkhada, R., Panelo, C., \& Solon, O. (2008) Underutilization of Social Insurance among the Poor: Evidence from the Philippines. PLoS ONE, 3(10), e3379. https://doi.org/10.1371/journal.pone.0003379

Ramos, V. B., Gabriel, A. G., \& Mangahas, T. L. S. (2020). Access to universal health care in the Philippines: The challenges of ethnicity, barriers, and inequities. Unpublished, SAGE Open, Manuscript ID SO-19-1873.R2

$\begin{array}{llll}\text { Republic Act } & 10606 & \text { (2013). Accessible }\end{array}$ https://www.philhealth.gov.ph/about_us/ra10606.pdf

Republic Act No. 7875 (1995). Accessible at https://www.philhealth.gov.ph/about_us/ra7875.pdf

Rizal, P. C. (2017). Lingap Para sa Bayan: One-stop shop for health services opens in Davao. DavaoToday.com. Accessible at http://davaotoday.com/main/economy/health/lingap-para-sa-bayan-one-stop-shop-for-health-s ervices-opens-in-davao/

Silfverberg, D. V. (2016). PhilHealth coverage in the informal sector: Identifying determinants of enrollment. Philippine Institute for Development Studies. Accessible at https://think-asia.org/bitstream/handle/11540/6441/pidspn1602.pdf?sequence=1

Smith, J. C., \& Medalia, C. (2015). U.S. Census Bureau. Current Population Reports, pg 5 
Health Insurance Coverage in the United States: 2014, USUS. Government Printing Office, Washington, DC.

Steinwachs, D. M., \& Hughes, R. G. (2008). Health Services Research: Scope and Significance. In: Hughes RG, editor. Patient Safety and Quality: An Evidence-Based Handbook for Nurses. Rockville (M.D.): Agency for Healthcare Research and Quality (U.S.); 2008 Apr. Chapter 8. Available from: https://www.ncbi.nlm.nih.gov/books/NBK2660/

Suerte (2010). "Conducting Systematic Reviews and Operations Researches on Specific Issues and Selected Priority Public Health Program. "University of the Philippines." Philippines Institute for Development Studies Discussion Paper Series -2010-02, Manila

Newman, B. M., \& Newman, P. R. (2020). "Chapter 4-Dynamic Systems Theory." In Theories of Adolescent Development, 77-112. Academic Press, 2020. https://doi.org/10.1016/B978-0-12-815450-2.00004-8.

Tobe, M., Stickley, A., del Rosario, Jr. R, \& Shibuya, K. (2013). Out-of-pocket medical expenses for in-patient care among beneficiaries of the National Health Insurance Program in the Philippines Health Policy and Planning, 28(5), 536-548, https://doi.org/10.1093/heapol/czs092

Tomacruz (2009). OPB Expansion to All PHIC Members and Private PHC Providers: Feasibility Analysis. European Union Technical Assistance to the Health Sector Policy Support Program. December. Accessible at https://pcw.gov.ph/republic-act-7875-national-health-insurance-act-of-1995/

The World Bank (2014). Poverty and Health. Accessible at https://www.worldbank.org/en/topic/health/brief/poverty-health

Twersky, F., Buchanan, P. \& Threlfall, V. (2013). Listening to Those Who Matter Most, the Beneficiaries. Accessible

at https://ssir.org/articles/entry/listening_to_those_who_matter_most_the_beneficiaries

Woelfel, J. A., Patel, R. A., Lee, H., Chu, S., Ranson, C., Patel, B., Italia, U., Walberg, M. P., Carr-Lopez, S. M., \& Galal, S. M. (2015). An overview and study of beneficiaries' knowledge, attitudes, and perceptions of the medicare part d benefit. The Consultant pharmacist: the Journal of the American Society of Consultant Pharmacists, 30(2), 101-111. https://doi.org/10.4140/TCP.n.2015.101.

\section{Copyright Disclaimer}

Copyright for this article is retained by the author(s), with first publication rights granted to the journal.

This is an open-access article distributed under the terms and conditions of the Creative Commons Attribution license (http://creativecommons.org/licenses/by/4.0/). 